\title{
Acute Renal Failure with Renal Papillary Necrosis
}

National Cancer Institute

\section{Source}

National Cancer Institute. Acute Renal Failure with Renal Papillary Necrosis. NCI

Thesaurus. Code C35473.

Sudden and sustained deterioration of the kidney function with decreased glomerular filtration rate, and concommittant necrosis of the renal papillae; representative causes include sickle cell disease, heave analgesic use, diabetes mellitus, and pyelonephritis. 